\title{
The Empirical Basis of Medicine in search of Humanity and Naturalistic Psychotherapy in search of its Hermeneutic Roots
}

\author{
(C) 2010 (English) Pio Scilligo
}

This article was originally published in Italian as 'La base empirica della medicina alla ricerca di umanità e una psicoterapia naturalistica alla ricerca delle sue radici ermeneutiche' in: "Psicologia Psicoterapia e Salute" 2006, Vol.12, No. 1, 1 - 30. The IFREP-93' review. This translation appears with the kind permission of IFREP93.

\section{Introduction}

Neurobiological research in the medical field, the regulation of psychotherapy and the vigorous quest for recognition of the profession of counselling are some of the many factors that may directly affect people's well being. These factors on one hand offer new ways of changing our lives for the better, with less pain and open to hope, and on the other they are steps of a progress that may actually worsen the conflict of interest between the medical, psychological and helping professions.

The entire population would benefit from a strong collaboration between those professions and from a better appreciation of their respective areas of competence. The benefits could be financial too, as cooperation would improve the efficiency of the existing structures and the recuperation of the assets currently employed in power and competency struggles. The capital saved could then be used to distribute responsibilities and professional knowledge on the basis of their suitability and effectiveness for prevention, treatment and cure.

In this article I will be evaluating some basic assumptions that guide the medical field and the social sciences and that, when satisfied, improve the usefulness of therapeutic or preventive interventions, allowing the individual to access and function in a mutually supportive social network.

\section{Empirical evidence in medicine and dissemination}

Thanks to the empirical research it is possible to discover new ways of intervention and to improve those already existing. Many types of intervention believed to be useful and effective can be tested and evaluated through highly reliable methodological procedures; as a result of this close examination they can be declared not useful or even harmful in spite of their being widely used. An example coming from the medical field is the use of Hormonal Replacement Therapy (HRT) that had been a popular choice for the cure of post menopausal osteoporosis. After a careful scientific analysis this therapy turned out to be not only ineffective for preventing coronary disease (Manson et al., 2003), but was correlated also with a $26 \%$ increase in the risk of breast cancer (Chlebowski et al., 2003). Unfortunately the illuminating results of scientific research are often not adequately divulged and so the corrective interventions are not applied or are accepted only after many years. As an historical example, in an experiment carried out by a ship captain in 1601 , sailors of one ship on a long trip to India were given three spoons of lemon juice daily in addition to the regular diet, and on the other three ships on the same trip the sailors had an identical diet but no lemon juice. During the first half of the journey, $40 \%$ of the sailors, 110 out of 278 , died on the ships where the lemon was not given, while on the experimental ship, where the lemon was consumed, nobody died. Despite this astonishing result it took 264 years before it became compulsory to add vitamin $C$ to the diet of sailors of the English merchant fleet (Berwick, 2003). 
Today the implementation of changes suggested by research evidence is much faster, on average ranging from 15 to 17 years (Institute of Medicine, 2001). However there are instances that show a rapid circulation and recognition of the results of research; an example is the case of arthroscopic surgery, an operation for osteoarthritis and commonly practiced until a few years ago. The efficacy of this procedure was tested in the late nineties in a controlled experiment involving studying 2 experimental groups of patients who had an arthroscopic operation of either 'shortening' or 'washing', and 1 control group of patients who were led to believe they had had the surgery but hadn't. The surprising results showed no significant difference between the conditions of patients of any of the groups, either immediately after the operation or later at follow up. As a consequence of this study the arthroscopic procedure was abandoned altogether (Moseley et al., 2002).

There are diverse factors influencing why information coming from results of scientific research is being used in practical application much more quickly today than in the past. Three prominent factors were presented by Barlow (2004), the foremost being the rapid growth of and depth of the understanding of the nature of much pathology, and the consequential adoption of new and more effective interventions. The second factor seems to be the substantial improvement in the quality of clinical research. In fact the external and internal validity of experiments is now stringently controlled; the introduction of analysis plans has allowed more advanced data analysis, and nowadays research is carried out in various environments so that the generalization of the results can be wider and the effects of the theoretical bias of the researchers becomes better controlled. The last factor influencing the dissemination of research is that worldwide there is a new awareness of the ineffectiveness of many health interventions, accompanied by the vertiginous increase of their costs, which together fuel the motivation to find new treatments of sound value.

\section{Evidence-Based Medicine, EBM}

The improved quality of the research on the effectiveness of treatments and its rapid circulation are also a derivative of the recent innovative approach to medicine defined as Evidence-Based Medicine (EBM). This approach in fact aims at using in clinical practice only those treatments that have been tested empirically.

One important purpose that underlines the spirit of EBM is articulated in its definition, as it does not only include the literal meaning of medicine based on empirical proof, but goes well beyond, especially if we take into consideration the intent that inspired it. David Sackett (Straus et al., 2005), one of the most important promoters of EBM, defines it as the integration of the doctor's personal and clinical competences with the results of external clinical evidence obtained by systematic research (Sackett et al., 1996). Three aspects are fundamental to this definition:

a. clinical proficiency, understood as the accumulated experience, training and clinical skills of the doctor;

b. what the person being treated brings to the relationship with the practitioner: their own preoccupations, their expectations, their own individual desires or values;

c. external clinical evidence attained by research that employs scientific methodology (Sackett, 2003).

Hence EBM maintains that the research evidence in itself is not enough to determine the process of the cure of the patient but it is the full integration of the above three components in the clinical interventions that can improve the patient's quality of life and the best clinical result. The practice of EBM begins with the encounter with the person who asks for the intervention; such encounter generates an evaluation of the effects of therapy, the usefulness of diagnostic tests, the prognosis and the etiology of the complaint. Hence the cure is determined by the complex process of accounting for and interpreting every single aspect that may take part in it.

\section{Empirical evidence of effectiveness in the psychological field}

In the psychological field important steps have been taken with the aim of identifying models of psychotherapy treatment that are scientifically proven, or EST (Experimentally Supported Therapies), to become the interventions of choice. Identifying such therapies has put many experts of psychological research on the defensive (Westen et al., 2004; Scilligo, 2004; see also Scilligo 1994) for they maintain that such choices lack a wider vision and attempt to apply medical criteria to psychology without considering the substantial differences between them (Scilligo, 2004). Moreover, according to Sackett et al. (2003), EBM involves attention to empirical verification as well as the use of the doctor's own human experience and openness to the person wishing to be cured, to understand them, welcome them and establish a strong collaboration.

The issue of the substantial difference between medical interventions and psychological ones will be discussed below, but I will now examine the research in the psychotherapy field and how data from such work struggles against economic pressures and the lack of a timely distribution.

One intervention aimed at distributing the results from empirical research on mental health is the allocation of funds for their diffusion to the public. In 2003 the Department of Health and Social Services in the United States granted 3.2 billion dollars to the SAMHSA (Substance Abuse and Mental Health Services Administration) to be used in the dissemination of 
information on physical and mental therapeutic interventions based on research; in the following 3 years, 8.5 billion dollars were allocated to 9 states for the same purpose. Here in Italy, perhaps we can see the recognition of private training institutions for psychotherapy as an instrument of diffusion of scientific knowledge in the sphere of psychological interventions.

However, it has emerged that these allocations of funds do not necessarily ensure an increase of information about the impact that psychological interventions can have on the public. For example, the results of a study carried out by Olfson et al. (cited in Barlow, 2004) on the use of psychotherapy leave us perplexed. Analyzing the available therapies for depression, they found that between 1987 and 1997 a growing number of people turned to treatment. However the number of people using antidepressants grew from $37.3 \%$ to $74.5 \%$ while the number of those who used psychotherapy diminished from $71.1 \%$ to $60.2 \%$. However, these percentages should be taken with due care as their definition of psychotherapy included all sorts of counselling, including drug counselling to encourage compliance.

Even more surprisingly, another statistic relative to the same period shows that the proportion of people suffering from depression who received psychotherapy from doctors grew from $68.9 \%$ to $87.3 \%$, while the proportion of treatments carried out by psychologists fell from $29.8 \%$ to $19.1 \%$. In addition, the number of psychotherapy sessions diminished notably. It is likely that this is partially due to a desire for immediate effects, which may be short lived, and not considering that the combined use of psychological and medical treatments together ensures longer term positive results and a lower risk of relapse (Barlow, 2004).

Below is a short synthesis demonstrating that psychological intervention is more effective in the long term than medical intervention.

\section{The health service and the impact of psychological treatment.}

The Journal of the American Medical Association and the New England Journal of Medicine are two publications well known for the rapid dissemination of innovative treatments based on sound empirical research. These two scientific journals publish psychological research evidence with the same stringent criteria of scientific rigor as it is found in the research of arthroscopic surgery. The analysis of evidence in these two prestigious journals shows that for a given disturbance, psychological interventions which use innovative procedures are more effective than current pharmacological or alternative therapy interventions. Several studies of stress-induced incontinence in women showed that psychological treatments were more successful when compared with medication or alternative therapies (Burgio et al., 1998; Goode et al., 2003). Another study on insomnia also shows the marked effectiveness of psychological treatment, compared with medical therapy or a placebo, either in terms of immediate effect or follow-up (Morin et al., 1999). A more recent study carried out in communities of Alzheimer's disease sufferers, similarly shows an improvement of their depressive states and physical health; the intervention also had a positive effect in delaying institutionalization (Teri et al., 2003). Yet another research reports an improvement of psychological interventions compared to traditional medical and alternative treatments in those who show Gulf War Veterans' Syndrome, a complaint with multiple symptoms and characterized by persistent pain, fatigue and cognitive impairment (Donta et al., 2003).

Considering more common psychological disturbances, a major study of the treatment of chronic depression has shown that psychological interventions and interventions using antidepressant medication are equally effective; moreover the combined use of both psychotherapy and medication gave results that were better than for each intervention alone (Keller et al., 2000). A study on panic by Barlow, Gorman, Shear \& Woods (2000) showed that psychological therapy was as effective as drug-based interventions when recorded immediately after treatment and at follow up, but the psychological treatment had a longer lasting effect as it involved less frequent relapses. Yet another study, on the treatment of depression among marginalized young women, shows that the psychological intervention produced better results compared to the services offered by the community agencies and showed equal effectiveness compared to pharmacological treatment. For this research, medical treatment had a certain advantage over the psychological as the latter was received by the women with some resistance (Miranda et al., 2003); for this study there is no follow-up data available yet.

However it is important to note that each of these studies has a different complaint as focus: from depression to incontinence and panic, thus the psychological interventions were necessarily of diverse nature.

Over the last decade hundreds of studies have tested psychological interventions using the stringent criteria of scientific research (amongst others, Baskin et al., 2003; Westen \& Morrison, 2001; Westen, Novotny, \& ThompsonBrenner, 2004). Such criteria include advanced effect measurements, inclusion of the subjects with and without co-morbidity, often utilizing plans of analysis that involve testing different treatment centres, and careful control of the theoretical bias of the experimenters (Luborsky et al., 2002). These studies have also been reviewed, including meta-analysis, by the US National Institute for Mental Health and by the UK's National Institute for Mental Health (Roth \& Fonagy, 1996), by national associations (Chorpita et al., 2002) and by professional

bodies such as the American Psychiatric Association. These studies concerning psychological and physical 
disturbances in adults or in children, from fears to vascular disease and cancer, have been subjected to

critical review (for example, Barrett \& Ollendick, 2003; Gatchel \& Turk, 2002; Gatz et al., 1998; Kazdin \& Weisz, 2003; Nathan \& Gorman, 1998, 2002; Roth \& Fonagy, 1996, 2004; Smith, Kendall, \& Keefe, 2002). From all the collected evidence it often emerges that for any specific complaint it is possible to obtain highly positive results when their treatments include combined interventions.

A clear conclusion that can be safely drawn from this research is that psychotherapy of various theoretical approaches is effective when compared with any other treatment, including alternative psychological ones. In clinical practice, for major depression both drug therapy and psychotherapy produce similar effects and both are more effective than the placebo.

However for major depression most well planned treatments produce positive effects or the depressive condition disappears on its own, almost always to returns some time later (Judd, 1997). An effective treatment, whether medical or psychological, should eliminate the reappearance of depressive states. On the basis of the most recent research, psychotherapy produces longlasting effects on its own, even when used for major depression (for example, Fava et al., 1998; Hollon \& Beck, 2004; Hollon, Thase, \& Markowitz, 2002; Paykel et al., 1999; Teasdale et al., 2000).

Barlow (2004) concludes the evaluation of these studies claiming that any analysis that aims at comparing results relative to different pathologies will not provide conclusions that make sense.

Also, most protocols used in the psychological treatments studied come from the laboratories of psychological sciences, more specifically the cognitive and behavioural sciences that are strongly linked to social psychology and interpersonal processes. Such protocols have been adapted to be used in clinical practice for psychological disturbances (Bourton, Mineka \& Barlow, 2001).

Furthermore, the psychological interventions studied are a collection of psychotherapies based on different theoretical approaches, which are not static. In fact such approaches are becoming less and less distinguishable between each other as they have started to borrow sections of different theoretical justifications based on scientific verification of their efficacy. For example, one of the preferred treatments for drug and alcohol abuse based on empirical research derives partly from the non-directional Rogerian model of counselling (Burke, Arkowitz, \& Mencola, 2003; Miller \& Rollnick, 2002).

Finally, from recent analysis of treatments for mental health issues, it is clear that such issues are quite serious so the findings may not be applicable to milder disturbances (Stirman, DeRubeis, Crits-Christoph, \& Brody, 2003).

\section{Towards which future?}

Scientific evidence has led to the adoption of new interventions deriving from different theoretical psychological approaches; these are the community assertion treatments, community support interventions, motivational interviewing, parent education (with the aim of identifying disturbances in children), stress and pain management, and some with names that evoke a more deliberately psychotherapeutic aim, such as interpersonal systemic therapy, family therapy, cognitive-behavioural therapy, dialectic behavioural therapy. All these treatments are based on the establishment of the therapeutic alliance and on building a positive attitude towards change; they use counselling skills in order to support the suffering individual in learning to make a better use of his/her own resources. Barlow (2004) suggests that all these interventions should come under the generic name of "Psychological treatments".

These new evidences bring to the fore the importance of the collaboration between the professionals, whether psychologists or not, who deliver the scientifically based interventions in the real and human world.

If the successes of these collaborations between practitioners of different orientations and competencies were widely and publicly known, perhaps we would see an increase in the use of psychological therapies as it is common knowledge that given the choice, the public prefers psychological interventions to medication (for example, Hazlett-Stevens et al., 2002; Hofmann et al., 1998; Mitchell et al., 1990; Wilson \& Fairburn, 2002; Zoellner et al., 2003).Sometimes scientific research has seemed to encourage interventions that are heavily reliant in the use of techniques, as in the case of EST (Westen, et al. 2004). However, recent data shows that psychological treatments require clinical competency and a solid therapeutic relationship to increase their effectiveness, especially for serious psychopathologies (Klein et al., 2003; Norcross, 2002).

The outcome of the treatment depends on important variables such as the experience of the therapist (Huppert et al., 2001). Psychotherapists with longer experience are able to use tailored interventions to adapt to the different patients styles, with proven efficacy of the results (Beutler, Moleiro, \& Talebi, 2002; Castonguay et al., 1996). For example, the experienced psychotherapists who had adopted less directive 
communication with non motivated patients got better results than the psychotherapists who remained directive in their interventions (Beutler \& Harwood, 2000), within the remit of the specific patient psychopathology.

In cases of mild disturbances, the competence of the psychotherapist found a good complement in the use of self-help books (Ehlers et al., 2003) and in the use of purpose-built computer programs (for example, Kenardy et al., 2003; Norcross et al., 2003).

In synthesis, Barlow (2004) maintains that there are three basic principles to evaluate the effectiveness of psychological treatments:

a. The appropriateness of the psychological intervention for the disturbance or the medical or psychological problem;

b. The necessity of accounting for the characteristics of the therapist and the patient in the treatment plan;

c. The evaluation of the treatments must take into account the specific situation within which treatment is carried out.

In his conclusions, Barlow (2004) makes recommendations on who should carry out the interventions for mental health. Scientific research offer rich and differentiated indications that show that the specialist who is best trained is the psychologist. Special consideration should be given to the clinical experience of those who provide psychological help, as it seems to imply clinical qualities which affect their effectiveness in ways not predicted by empirical research.

Barlow himself underlines the need to consider each specific context and the variables of the psychotherapist; it is important to consider in what measure the results of controlled clinical trials carried out in laboratories can be directly applicable to different, real environments. This is the same criticism made of experimentally validated therapies: as well as giving an important widening of the horizon, they risk imparting a restricted vision of problems that are humanly complex rather than technical issues.

The rich scientific research has shown that the factor of "clinical competency" of the therapist is not reducible to technical competence, but includes some very complex aspects of alliance, motivation and understanding of a variety of specific contexts and pathologies. Thus the need to consider how to measure and describe this interconnected complexity of factors that seem exquisitely human, perhaps not detectable by empirical research methods. Nevertheless, even in this view that recognizes the complexity of interventions on human problems, there is the risk of becoming experts of 'nails' because we hold a very good 'hammer', ignoring that people don't live on nails, however useful they may be. It is not by chance that EBM gives importance to the dialogue between the practitioner and the patient, a dialogue that becomes the creative source to understand the nature of the intervention in its complexity.

The evaluation of the psychological interventions with the three conclusions of Barlow (2004) shows that issues of meaning appear on the edge of the world of scientifically proven interventions.

This is what I am going to look at, to show that the intervention, in human circumstances, needs a wider understanding which includes both the empirical verification and the subjective understandings of the person.

\section{The Horizon of psychology in the western world}

The enthusiasm for empirically validated interventions is a derivative of Anglo-American psychology, which seeks to emulate the approach and methodology of natural sciences and medicine in general, in the hope of achieving the same levels of success. Such a vision is usually referred to as naturalism (Taylor, 1989, Scilligo, 2004). A basic tenet of naturalism is that human life is essentially one of the manifestations of nature, therefore to be studied and explained according to science. Science is a rigorous and objective discipline that mostly uses controlled experiments producing, as far as is possible, strictly objective descriptions of the human phenomena, independent from value judgements and neutral respect to them and to culture (Christopher, J.C., et al. 2000).

A key aspect of naturalism implies, using a famous quote from Max Weber, the "disenchantment from the world" or its secularization through objectification. In this view, the world is made of objects without meaning, in a causal relationship between them; often such a world is seen as the real and only world, even if the world of human encounters, shared intentions, moral struggles and quest for meaning continue to exist. One consequence of this objective vision of the world is a limitless subjectivity, in which values and meanings are seen as being constructed by the individual and projected onto the world.

Human identity lives inside each person and there is an infinite gap between individuals and the world, either natural or social. In this perspective people are seen as separate individuals, as discrete atoms of experience and action, linked in various ways to social groups competing against each other and trying to overcome the inevitable conflicts with others through negotiation and alliances.

In this type of world, freedom is conquered at the cost of alienation and emotional isolation, partly because such a world eliminates the possibility of deep sharing of values and lasting social bonds coming from human experience (Bellah et al, 1985; Cushman, 1990; Etzioni, 1996; 
Sandel, 1996).

Epistemology and scientific research develop reliable methods that guarantee a completely objective knowledge of reality, without the contamination of subjective desires and evaluations. Random sampling and double blind trials are necessary to anchor the knowledge in the objectivity so as to be able to make accurate predictions that structure reality in preferred modes. It is a matter of having the world represented in the mind to coincide with the world that is objectively out there, which has determined properties, independent from the cultural practices and beliefs. Knowledge, in this vision, essentially means the correspondence between internal beliefs and external reality. The person is seen as a subject who knows, thanks to the method of questioning, for which the only certain knowledge is of their own self that can potentially be known. The self is an isolated spot, completely cut off from a world of rough objects (Taylor, 1995).

The subject-object ontology and its representational epistemology has become the cornerstone of the social sciences of the twentieth century and they permeate wide sections of modern culture and thought. Objectivism has become "the belief that an a-historical permanent matrix exists, to which we can refer, to determine the nature of rationality, knowledge, truth, reality, of the good and the right" (Bernstein, 1983, p.8 cited in Christopher et al., 2000). In this objective vision the scientist is a detached and neutral observer, able to uncover social and psychological universal truths that are a-historical and timeless.

\section{Objectivism is a problem for the social and psychological sciences}

A first difficulty encountered by objectivism applied to social and psychological sciences is that "objective" research, despite great efforts, is still a long way from achieving the levels of scientific rigour of the natural sciences. The aspiration to develop well constructed theories, able to predict and control, as with the natural sciences, remains a dream (Christopher et al., 2000). Even the most sophisticated knowledge, that describes various configurations of correlated variables, does not allow any instrumental control over events that comes close to what has been obtained in the physical, biological and engineering sciences. Faced with such a vast failure, many academics maintain that research on human sciences is using a methodology that does not suit them, or only approximately.

For example, Gergen (1982) claims that there is a fundamental difference between the phenomena which interest the natural scientist, and those studied by the social-behavioural scientist. There is no real justification for the immense effort being made to prove empirically the fundamental laws of human behaviour. It would seem that there are very few regularities in human behaviour that are not subjected to significant changes. Secondly, it could be argued that the efforts of the social sciences to emulate natural sciences are based on an un-real and distorted understanding of the natural sciences themselves. Post-positivist philosophers, such as Feyerabend (1978), Kuhn (1970), Laudan (1977; 1984), Shapere (1984), Kitcher (1993) and Suppe (1977) convincingly argue that the positivist philosophies of science, with their belief in objectivism, are unable to present and understand what actually happens in the process of the natural sciences. The revisionist thinkers today insist on the deeply interpretative and hermeneutic dimensions of sciences; according to them, observation is dependent on the theory and the confirmation or refusal of the theory can be seen as a convention influenced by values such as usefulness or parsimony. These changes in the philosophy of the natural sciences invite us to think that the social sciences are constructed on the basis of false assumptions. Thirdly, objectivism has led to a paradoxical and dangerous idealisation of method, actually an idolatry of method. The social sciences usually treat theorization as separate and subordinated to scientific method, used to obtain knowledge (Slife and Williams, 1995, Scilligo 2009). The theories and predictions of the scientific hypotheses, wherever they are coming from, are valid and acceptable only in as much as they are tested and validated by methods that have been devised independently from any theory.

However, the methods are in fact applied according to theoretical and philosophical beliefs concerning the nature of things and how we can know them. So, the method itself is a theory, a philosophy that is based on assumptions about the world and from such assumptions emerge important implications. Such assumptions ignore some factors and evaluations while others are accepted without any proof, and smuggled in by 'philosopher's magic' and disguised as "scientific method" (Slife and Williams 1997). Finally the unrealistic and distorted position that objectivism proposes, paves the way to a thinking that is all or nothing, where the only alternative to objectivism remains relativism, a relativism that puts the thinker into a condition without a way out.

Examples of this relativism are found in constructivist and postmodern social theories, which completely abandon the concept of knowledge as representation and undermine any efforts to anchor understanding (Gergen, 1985, 1994; Rorty, 1979, 1982). For example, Gergen (1985) maintains that social constructionism goes beyond the traditional objective-subjective dualism, because psychological research ignores the notion that experience is the touchstone for objectivity. The socalled descriptions of one's own experience would be nothing other than "linguistic constructions guided and formed by historically contingent conventions of discourse". So truth can not be derived from the method; there is no right procedure to guarantee the objectivity of results and theories. Instead, social constructionism offers "accounts of success mainly linked to the ability of 
the academic to invite, convince, stimulate and thrill spectators and not to criteria of veracity" (Gergen, 1985, p. 270).

\section{Towards an integrated vision of the human situation}

Notwithstanding the clear limits of a representational vision of objectivity in empirical research applied to human sciences, the current trend is to remain with scientific reductionism instead of finding ways that respond to the needs of a world that is in need of opening itself up to the subjective without the excesses of constructionism or constructivism. It is not hard to see that today the alienated person, detached from the world in which he/she lives, in reality is at the same time a moral and scientific idealization.

The modern self, without important links to the natural and social world, in fact connects with it through the central moral ideals of the modern world, such as freedom as autonomy of the self, individual responsibility, and the use of one's own judgment to find one's fulfilment within the self (Taylor, 1995). This self is well equipped with freedom and rationality to deal with its own structure and the world around, to change them both at will or resist pressure to conform and to pursue self-actualisation.

Representational philosophy is well suited to Western culture, where the ability to obtain freedom is at the cost of alienation, and where there is such an emphasis on possessing and controlling nature and the self, even at the expense of other types of social, moral and spiritual values. Even the aspiration to know an independent reality in science is well adapted to the anti-authoritarian and emancipatory moral vision of modern times (Richardson, 1989). Such a vision promotes and protects individual autonomy as a priority, tending to ignore other values and virtues such as the "redemptive power of suffering, the acceptance of one's own destiny, and adhesion to tradition, self limitation and moderation" (Frank, 1973, p.7 cited in Christopher et al, 2000).

The search for certainty through representational epistemology and exaggerated individualism is also connected to modern urban life which leads to a weakening of state support and the dissolution of human bonds and shared obligations (Berger, 1977; Berger, 1979). Hence the illusion of an impregnable individualism and of an invincible knowledge. Dunne (1996) sees this self with its appearance of separateness and ability to manage nature as a disguise for a sense of failure and precariousness of the modern condition of people uprooted and emotionally isolated. For him, it is the result of Cartesian angst which requires the human being either to find an Archimedean point or to be unable to escape the dark forces of intellectual and moral chaos (Bernstein 1983, cited in Christopher et al, 2000). In other words, the application of the principles of clear separateness and independence of the subjective and objective world, as seen by the naturalistic philosophy, transforms the human agent into a subject that knows the world through a correct representation and aims at theorizing and controlling it by technology. According to many studies this produces an inordinate individualism, alienation, the dissolution of social bonds, an exaggerated preoccupation with possessing and controlling and the incapacity of tolerating healthy limits. The ontology of the subject-object, according to which the modern individual is detached and de-contextualised, guarantees some important values, such as personal autonomy, basic human rights, and a critical position towards tradition. But at the same time there is the risk of totally eliminating the notions of community, tradition and ethical values that go beyond the rights of the individual as well as the possibility of implementing procedures aimed at making absolutes of the ideals of liberty and technical control (Sandel, 1996).

Contemporary hermeneutics can open up an alternative landscape. It offers the promise of promoting a postNewtonian understanding of the social sciences and psychology, without undermining the post positivistic orientation within the natural sciences; such opening of horizons sees knowledge as essentially interpretative and indicates the substantial differences in the explanations of the human sciences and the natural sciences. The hermeneutic conception does not exclude the use of abstraction and objectivization of the natural sciences. It is possible to stand back, through abstraction, from the meanings and the significant relationships of life and consider them, including human behaviour, as processes or neutral events, or structure them in terms of cause-effect, a dynamic momentarily detached and objectified. This neutral distancing and abstraction favours the development of a quantitative and fragmented cognitive style in the individual, commonly found in the business and industrial world. But in the social and psychological field when this cognitive style is made the only choice it leaves out the experiences and emotions that are spontaneous and contemplative and leads to the destruction of relatively cohesive communities where people have always found support, solidarity and meaning throughout history (Berger, 1977). The momentary objectified detachment should be reinterpreted within a wider interpretive framework

\section{Different factors intervening in the broadening of the horizon}

Gadamer (1975) claims that precognition is the basis of any knowledge; knowledge is an interpretation always embedded in a lived tradition. According to this view, the effort to reach an objective knowledge, a-historical, free from values, is not only impossible but also flawed.Today a postmodern hermeneutic exists and shows that there are cultural values that penetrate it from every side, despite the efforts of psychology to be neutral and objective (Christopher, 1999; Christopher, Christopher \& Dunnagan, 2000; Cirillo \& Wapner, 1986; Cushman, 
1995a; Hogan, 1975; Kirschner, 1996; Richardson, Fowers, \& Guignon, 1999; Sampson, 1977, 1988; Spence, 1985; Woolfolk, 1998).

A second reason that knowledge can be objectified, if not parenthetically and in non-absolute terms, is due to our historical nature. The human subject is always placed within a particular horizon based on personal and cultural factors. From this viewpoint, hermeneutics is not only a method to guide interpretation but is also a social ontology that explains how the human agent is necessarily embedded in a social and cultural context. Heidegger (1962), in conceiving the being in an interpretative activity, proposes an alternative ontology to that of the isolated and unconnected so central to the Newtonian and Cartesian conception. For Heidegger being-in-the-world is a vision of the person that is neither dualistic nor individualistic: human existence is a becoming (Heidegger, 1962, p.426); the lives of individuals have a temporal and narrative structure, a developing and extending from birth to death.

For hermeneutic thinkers the language of science applied to the study of human beings is relatively poor. In science human beings are studied from a distance (Slife \& Williams, 1995) while the only imaginable human agent is born of the "logic of asking and responding" (Gadamer, 1975 , p.333) within a space of questioning. This is a space for a critical dialectic of values and ways of acting in the context of other commitments and moral intuitions which are a part of the living-out of traditions by people in dialogue. Lives and traditions are in continual flux about religious and scientific contents, and even the defects and meanings of the Enlightenment tradition that permeates us are widely discussed.

\section{Hermeneutic Dialogue}

This widening of horizons needs a hermeneutic dialogue that consists of a process in which meaning is given to significance, to interpretations, to the tasks of self and of others when they differ from our own. Genuine understanding will be found in the fusion of horizons.

The first step in hermeneutic dialogue is that of understanding what the people in the dialogue hope, mean and intend. It is a circular game between opening and application. The initial phase of opening (Gadamer, 1975 ) is based on the presupposition that nobody has an advantage in truth and that the other could have something important to communicate to us. Genuine openness implies giving the other momentary authority to challenge the beliefs and prejudices of the partner in dialogue (Warnke, 1987), in an effort to understand how the interlocutor can have their own belief and way of living with its own fullness of truth and meaning. The "fusion" happens when we are able to take a respectful position, open to the other, when we concede to the other the authority to put into discussion our own assumptions and deepest values. According to Gadamer (1975), this is the most authentic way to put ourselves in relation with others. A second phase of dialogue, application, implies critical testing of the intuitions and viewpoints that emerge from the opening, to see if they offer a better vision for the current situation and for the new circumstances and new challenges possible: what is learned is always modified by one's own circumstances and historical situation, never blindly accepted.

There are risks in the use of openness and application. The main risk of openness is conservatism (Warnke, 1987), which implies blind obedience to authority and rationalization of the status quo. One remedy for such non authentic rationalization is a later application of the new discoveries to one's own historical situation. The main risk of application is the opportunistic inter-pretation of the events and principles in a self-referential egotistical manner. The remedy for such arbitrary tendencies is again a later, often painful, opening to the challenges of others in which creative initiative and cognitive information continue their dance. Gadamer (1981) thinks that this continual process of challenge and response underlies not only the understanding of texts and other forms of discourse, but is also a factor of the game of tradition being played out.

In Gadamer's view we are always engaged in a continuous dialogue between the meaningful and historical preconceptions in which we are immersed and the continual control of what is assumed in the light of what the texts and interlocutors have to say. The human being is placed in an everlasting dialogue, in which the voices of the past are critically heard to find the truth applicable to the present. In this way, the horizon and the questions we raise are constantly transformed through ongoing dialogue (Gadamer, 1981).

\section{Psychology between objectivisation and interpretation}

From what we have see above it clearly emerges that the social sciences, including psychology, cannot limit themselves to the methodology of detached observation, so central to the naturalistic traditions. The philosophical, humanistic and religious traditions of the West see the social sciences impregnated with assumptions about the nature of people, society and relations between people and society. Even underneath the concepts of good society and good person there are assumptions (Bellah, et al., 1985). The presence of normative assumptions motivated Bellah et al. (1983) to claim that the social sciences are better described as a sort of moral inquiry. In this light the social sciences that intend to explain human action in a daily, concrete cultural context cannot be understood as a formulation of hypotheses and their confrontation with independent facts, for in this case the "facts" are lived-out exper-iences, mainly made up of the evolution of self-understanding and significance. 
Experimental, correlational, qualitative and other methods can be very useful to identify configurations or let hidden reality emerge from the human experience and the world. However, such methods cannot remain the only explanations or "objective" descriptions to which our way of thinking is accustomed. Their importance and their significance is a function of a wider interpretative effort, to give meaning to the human situation, under the control of a perpetual dialogue.

So one important conclusion is that the interpretative approach is not an alternative substitute for rigorous empirical research, indeed it complements it; hermeneutic is a meta-theory that gives a better explanation for the applications and discoveries of empirical sciences, fully aware that the interpretations reached are never definitive or certain. The interpretative vision sits well with methodological pluralism. In other words, we can say that a fundamental point of the theory and research of the psychological and social sciences is the clarification of meaning according to which we live and is not limited to the pure and simple precise prevision, but is a critical use of it. Sometimes the theory and research confirm and validate lifestyles, but they always interpret anew the social styles of living and so can bring to light errors, inconsistencies and failures and promote a transformation of the life in the present.

The interpretation and understanding of daily life through dialogue implies an inevitable exercise of our evaluation, an application of lived life (Christopher et al., 2000). For this, Bernstein (1978) maintains that the social sciences should be at the same time empirical, interpretative and critical. The theory and research of the social sciences essentially contains ethical and political aspects and is a particular way of seeking justice, love and wisdom in the practice of daily life.

\section{Conclusions}

This article has shown the trend in medicine, faithful to its empirical research and the principles of naturalism, to move towards a method of care which involves in a dialogue the person asking to be cured. We have shown how health psychology is moving in a direction that seeks to have a similar scientific basis as medicine. Through a short overview of research we have shown how the psychological sciences, adopting a naturalistic medical vision are able to demonstrate results that are comparable to those of medicine for the success it obtains and which are better over the long term. Success is put under post-positivist criticism for the negative effects of naturalism on the conception of the person and on the social network of human community. A proposal is made to enrich it by adding on an interpretative approach as a meta-theory that can create enough space for the empirical scientific approach and enhance it by establishing boundaries to an exaggerated and fictitious objectivism and an uncontrolled subjectivism. Moreover, it introduces an interpretative encounter with each person's historical experience and their links with tradition and culture, neutralising the pretences of absolute detachment from the great values of human life of the naturalistic approach and attributing the task of a moral hermeneutic debate to science.

Pio Scilligo PhD died on July 3rd 2009, after many years of making major contributions to the development of transactional analysis. This article is published posthumously because of its relevance to the aims of IJTAR to stimulate high quality research.

\section{References}

Barlow, D. H. (2004). "Psychological treatments". American Psychologist, 59, 869-878.

Barlow, D. H., Gorman, J. M., Shear, M. K., \& Woods, S. W. (2000). "Cognitive-behavioral therapy, imipramine, or their combination for panic disorder: A randomized controlled trial". Journal of the American Medical Association, 283, 2529-2536.

Barrett, P. M., \& Ollendick, T. H. (Eds.) (2003). Handbook of interventions that work with children and adolescents. West Sussex, England: Wiley.

Baskin, T. W., Tierney, S. C., Minami, T., \& Wampold, B. E. (2003). "Establishing specificity in psychotherapy: A metaanalysis of structural equivalence of placebo controls". Journal of Consulting and Clinical Psychology, 71, 973-979.

Bellah, R. N., Madsen, R., Sullivan, W. M., Swidler, A., \& Tipton, S. M. (1985). Habits of the heart: Individualism and commitment in American life. New York: Harper \& Row.

Berger, P. (1977). Facing up to modernity: Excursions in society, politics, and religion. New York: Basic Books, Inc.

Berger, P. L. (1979). The heretical imperative: Contemporary possibilities of religious affirmation. Garden City, NY: Anchor.

Bernstein, R. J. (1983). Beyond objectivism and relativism: Science, hermeneutics, and praxis. Philadelphia: University of Pennsylvania Press.

Berwick, D. M. (2003). "Disseminating innovations in health care", Journal of the American Medical Association, 289, 19691975.

Beutler, L. E., \& Harwood, M. T. (2000). Prescriptive therapy: A practical guide to systematic treatment selection. New York: Oxford University Press.

Beutler, L. E., Moleiro, C., \& Talebi, H. (2002). "Resistance in psychotherapy: What conclusions are supported by research?" Journal of Clinical Psychology, 58, 207-217.

Bourton, Mineka \& Barlow (2001) no reference listed in original article.

Burgio, K. L., Goode, P. S., Locher, J. L., Umlauf, M. G., Roth, D. L., Richter, H. E. et al. (1998). "Behavioral training with and without biofeedback in the treatment of urge incontinence in older women: A randomized controlled trial". Journal of the American Medical Association, 288, 2293-2299. 
Burke, B. L., Arkowitz, H., \& Mencola, M. (2003). "The efficacy of motivational interviewing: A meta-analysis of controlled clinical trials". Journal of Consulting and Clinical Psychology, $71,843-861$

Castonguay, L. G., Goldfried, M. R., Wiser, S., Raue, P. J., \& Hayes, A. M. (1996). "Predicting the effect of cognitive therapy for depression: A study of unique and common factors". Journal of Consulting and Clinical Psychology, 64, 497-504.

Chlebowski, R. T., Hendrix, S. L., Langer, R. D., Stefanick, M. L., Gass, M., Lane, D. et al. (2003). "Influence of estrogen plus progestin on breast cancer and mammography in healthy postmenopausal women". Journal of the American Medical Association, 289, 3243-3253.

Chorpita, B. F., Yim, L. M., Donkervoet, J. C., Arensdorf, A., Amundsen, M. J., McGee, C. et al. (2002). "Toward large-scale implementation of empirically supported treatments for children: A review and observations by the Hawaii Empirical Basis to Services Task Force." Clinical Psychology: Science and Practice, 9, 165-190.

Christopher, J. C. (1996). "Counseling's inescapable moral visions." Journal of Counseling \& Development, 75 (1), 17-25.

Christopher, J. C. (1999). "Situating psychological well-being: Exploring the cultural roots of its theory and research." Journal of Counseling \& Development, 77 (2), 141-152.

Christopher, J. C., \& Richardson, F. C. (2000,). "Philosophical hermeneutics: A metatheory to transcend dualism and individualism in Western psychology" in Smith K. D.(Chair), Metatheories in the natural sciences and in cross-cultural psychology. Symposium conducted at the International Congress of the International Association for Cross-Cultural Psychologists, Warsaw, Poland.

Christopher, S., Christopher, J. C., \& Dunnagan, T. (2000). "Culture's impact on health risk appraisal psychological wellbeing questions." American Journal of Health Behavior, 24 (5), 338-348.

Cirillo, L., \& Wapner, S. (1986). Value presuppositions in theories of human development. Hillsdale, $\mathrm{NJ}$ : Lawrence Erlbaum.

Cushman, P. (1990). "Why the self is empty: Toward a historically situated psychology". American Psychologist, 45 (5), 599-611.

Cushman, P. (1995). Constructing the self, constructing America: A cultural history of psychotherapy. Reading, MA, USA: Addison-Wesley Publishing Co, Inc.

Donta, S. T., Clauw, D. J., Engel, C. C., Guarino, P., Peduzzi, P., Williams, D. A. et al. (2003). "Cognitive behavioral therapy and aerobic exercise for Gulf War veteran's illnesses: A randomized controlled trial." Journal of the American Medical Association, 289, 1396-1404.

Dunne, J. (1996). "Beyond sovereignty and deconstruction: The storied self'. Philosophy and social criticism, 21, 137-157.

Ehlers, A., Clark, D. M., Hackmann, A., McManus, F., Fennell, M., Herbert, C. et al. (2003). "A randomized controlled trial of cognitive therapy, a self-help booklet, and repeated assessments as early interventions for posttraumatic stress disorder." Archives of General Psychiatry, 60, 1024-1032.

Etzioni, A. (1996). The new golden rule: Community and morality in a democratic society. New York: Basic Books.

Fava, G. A., Rafanelli, C., Grandi, S., Conti, S., \& Belluardo, P. (1998). "Prevention of recurrent depression with cognitive behavioral therapy: Preliminary findings". Archives of General Psychiatry, 55, 816-820.

Feyerabend, P. (1978). Against method. London: Verso.

Frank, J. D. (1973). Persuasion and healing: A comparative study of psychotherapy. New York: Schocken Books.

Gadamer, H.-G. (1975). Truth and method. New York: Crossroad.

Gadamer, H.-G. (1981). Reason in the age of science. Cambridge, MA: MIT Press.

Gatchel, R. J., \& Turk, D. C. (2002). Psychological approaches to pain management. ( $2^{\text {nd }}$ ed.). New York: Guilford Press.

Gatz, M., Fiske, A., Fox, L. S., Kaskie, B., Kasl-Godley, J. E., McCallum, T. J. et al. (1998). "Empirically validated psychological treatments for older adults". Journal of Mental Health and Aging, 4, 9-46.

Gergen, K. (1982). Toward transformation in social knowledge. New York: Springer-Verlag.

Gergen, K. J. (1985). "The social constructionist movement in modern psychology." American Psychologist, 40 (3), 266-275.

Gergen, K. J. (1994). Realities and relationships: Soundings in social construction. Cambridge, MA, USA: Harvard University Press.

Goode, P. S., Burgio, K. L., Locher, J. L., Roth, D. L., Umlauf, M. G., Richter, H. E. et al. (2003). "Effect of behavioral training with or without pelvic floor electrical stimulation on stress incontinence in women: A randomized controlled trial." Journal of the American Medical Association, 290, 345-352.

Haan, N., Bellah, R. N., Rabinow, P., \& Sullivan, W. M. (1983). Social science as moral inquiry. New York: Columbia University Press.

Hazlett-Stevens, H., Craske, M. G., Roy-Byrne, P. P., Sherbourne, C. D., Stein, M. B., \& Bystritsky, A. (2002). "Predictors of willingness to consider medication and psychosocial treatment for panic disorder in primary care patients." General Hospital Psychiatry, 24, 316-321.

Hofmann, S. G., Barlow, D. H., Papp, L. A., Detweiler, M. F., Ray, S. E., Shear, M. K. et al. (1998). "Pretreatment attrition in a comparative treatment outcome study on panic disorder". American Journal of Psychiatry, 155, 43-47.

Hogan, R. (1975). "Theoretical egocentrism and the problem of compliance". American Psychologist, 30 (5), 533-540.

Hollon, S. D., \& Beck, A. T. (2004). "Cognitive and cognitivebehavioral therapies." In M. J. Lambert (Ed.), Garfield and Bergin's handbook of psychotherapy and behavior change: An empirical analysis. New York: Wiley. 
Hollon, S. D., Thase, M. E., \& Markowitz, J. C. (2002).

"Treatment and prevention of depression." Psychological Science in the Public Interest, 3, 39-77.

Huppert, J. D., Bufka, L. F., Barlow, D. H., Gorman, J. M., Shear, M. K., \& Woods, S. W. (2001). "Therapists, therapist variables, and cognitive-behavioral therapy outcome in a multicenter trial for panic disorder". Journal of Consulting and Clinical Psychology, 69, 747-755.

In randomized controlled trials of psychotherapy representative of community Institute of Medicine (2001). Crossing the quality chasm: A new health system for the 21st century. Washington, DC: National Academy Press.

Judd (1997) no reference listed in original article

Kazdin, A. E., \& Weisz, J. R. (2003). Evidence-based psychotherapies for children and adolescents. New York: Guilford Press.

Keller, M. B., McCullough, J. P., Klein, D. N., Arnow, B., Dunner, D. L., Gelenberg, A. J. et al. (2000). "A comparison of nefazodone, the cognitive behavioral analysis system of psychotherapy, and their combination for the treatment of chronic depression." New England Journal of Medicine, 342, 1462-1470.

Kenardy, J. A., Dow, M. G. T., Johnston, D. W., Newman, M. G., Thomson, A., \& Taylor, C. B. (2003). "A comparison of delivery methods of cognitive-behavioral therapy for panic disorder: An international multicenter trial." Journal of Consulting and Clinical Psychology, 71, 1068-1075.

Kirschner, S. R. (1996). The religious and romantic origins of psychoanalysis. New York: Cambridge University Press.

Kitcher, P. (1993). The advancement of science: Science without legend, objectivity without illusions. New York: Oxford University Press.

Klein, D. N., Schwartz, J. E., Santiago, N. J., Vivian, D., Vocisano, C., Castonguay, L. G. et al. (2003). "Therapeutic alliance in depression treatment: Controlling for prior change and patient characteristics". Journal of Consulting and Clinical Psychology, 71, 997-1006.

Kuhn, T. S. (1970). The structure of scientific revolutions. Chicago: The University of Chicago Press.

Laudan, L. (1984). Science and values: The aims of science and their role in scientific debate. Berkeley: The University of California Press.

Luborsky, L., Rosenthal, R., Diguer, L., Andrusyna, T. P., Berman, J. S., Levitt, J. T. et al. (2002). "The dodo bird verdict is alive and well-Mostly". Clinical Psychology: Science and Practice, 9, 2-12.

Manson, J. E., Hsia, J., Johnson, K. C., Rossouw, J. E., Assaf, A. R., Lasser, N. L. et al. (2003). "Estrogen plus progestin and the risk of coronary heart disease". New England Journal of Medicine, 349, 523-534.

Miller \& Rollnick (2002) no reference listed in original article

Miranda, J., Chung, J. Y., Green, B. L., Krupnick, J., Siddique, J., Revicki, D. A. et al. (2003). "Treating depression in predominantly low-income young minority women: A randomized controlled trial." Journal of the American Medical Association, 290, 57-65.

Mitchell, J. E., Pyle, R. L., Eckert, E. D., Hatsukami, D., Pomeroy, C., \& Zimmerman, R. (1990). "A comparison study of antidepressants and structured intensive group psychotherapy in the treatment of bulimia nervosa." Archives of General Psychiatry, 47, 149-157.

Morin, C. M., Colecchi, C., Stone, J., Sood, R., \& Brink, D. (1999). "Behavioral and pharmacological therapies for late-life insomnia: A randomized controlled trial". Journal of the American Medical Association, 281, 991-999.

Moseley, J. B., O'Malley, K., Petersen, N. J., Menke, T. J., Brody, B. A., Kuykendall, D. H. et al. (2002). "A controlled trial of arthroscopic surgery for osteoarthritis of the knee". New England Journal of Medicine, 347, 81-88.

Nathan, P. E., \& Gorman, J. M. (1998). A guide to treatments that work. London: Oxford University Press.

Nathan, P. E., \& Gorman, J. M. (2002). "Efficacy, effectiveness, and the clinical utility of psychotherapy research." In Nathan, P. E. \& Gorman J. M. (Eds.), A guide to treatments that work $\left(2^{\text {nd }}\right.$ ed. $)$. New York: Oxford University Press.

Norcross, J. C. (2002). "Empirically supported therapy relationships". In J. C. Norcross (Ed.), Psychotherapy relationships that work: Therapist contributions and responsiveness to patients. London: Oxford University Press.

Norcross, J. C., Santrock, J. W., Campbell, L. F., Smith, T. P., Sommer, R., \& Zuckerman, E. L. (2003). Authoritative guide to self-help resources in mental health. (Rev. ed.). New York: Guilford Press.

Paykel, E. S., Scott, J., Teasdale, J. D., Johnson, A. L., Garland, A., Moore, R. et al. (1999). "Prevention of relapse in residual depression by cognitive therapy: A controlled trial". Archives of General Psychiatry, 56, 829-835.

Richardson, F. C. (1989). "Freedom and commitment in modern psychotherapy”. Journal of Integrative \& Eclectic

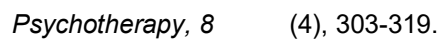

Richardson, F. C., Fowers, B. J., \& Guignon, C. B. (1999). Re-envisioning psychology: Moral dimensions of theory and practice. San Francisco, CA, USA: Jossey-Bass Inc, Publishers.

Rorty, R. (1982). Consequences of pragmatism. Minneapolis: Univinversity of Minnesota Press. 303-319.

Rorty, R. (1979). Philosophy and the mirror of nature. Princeton, NJ: Princeton University Press.

Rorty, R. (1982). Consequences of pragmatism. Minneapolis: Univinversity of Minnesota Press.

Roth, A., \& Fonagy, P. (1996). What works for whom? A critical review of psychotherapy research. New York: Guilford Press.

Roth, A., \& Fonagy, P. (2004). What works for whom? A critical review of psychotherapy research. ( $2^{\text {nd }}$ ed.). New York: Guilford Press. 
Sackett, D. L. , Richardson S.W., Rosemberg W. And Haynes, W. (1996), Evidence Based Medicine, Churchill Livingstone ed.

Sackett, D. L. (2003). La medicina basata sulle evidenze: come praticare ed insegnare I'EBM. Centro Scientifico Editore: Torino.

Sampson, E. E. (1977). "Psychology and the American ideal". Journal of Personality \& Social Psychology, 35 (11), 767-782.

Sampson, E. E. (1988)."The debate on individualism: Indigenous psychologies of the individual and their role in personal and societal functioning." American Psychologist, 43 (1), 15-22.

Sandel, M. J. (1996). Democracy's discontent: America in search of a public philosophy. Cambridge, MA: Harvard.

Scilligo, P. (1994). "La ricerca clinica e la prassi psicoterapeutica: una valle da colmare". In Scilligo P. De Luca M.L, Bastianelli L. \& Ceridono D. (eds), La ricerca in psicologia, vol. 4. Roma: IFREP, pp. 1-23.

Scilligo, P. (2004). "Tra scienza ed ermeneutica nella psicoterapia: un'analisi critica del naturalismo scientifico e vie di uscita". Psicologia Psicoterapia e Salute, 10, 1-19.

Shapere, D. (1984). Reason and the search for knowledge: Investigations in the philosophy of science. Boston: D. Reidel.

Slife, B. D., \& Williams, R. N. (1995). What's behind the research? : discovering hidden assumptions in the behavioral sciences. Thousand Oaks Calif.: Sage Publications.

Slife, B. D., \& Williams, R. N. (1997). "Toward a theoretical psychology: Should a subdiscipline be formally recognized?" American Psychologist, 52 (2), 117-129.

Smith, T. W., Kendall, P. C., \& Keefe, F. J. (2002). "Behavioral medicine and clinical health psychology". Journal of Abnormal Psychology, [Special Issue],70.

Spence, J. T. (1985). "Achievement American style: The rewards and costs of individualism."American Psychologist, 40 (12), 1285-1295.

Stirman, S. W., DeRubeis, R. J., Crits-Christoph, P., \& Brody, P. E. (2003). "Are samples in randomised controlled trials of psychotherapy representative of community outpatients? A new methodology and initial findings." Journal of Consulting and Clinical Psychology, 71, 963-972.
Straus S.E, Richardson W.S., Glasziou P., Haynes R.B.(2005). Evidence-based Medicine: How to practice and teach EBM. Edinburgh: Churchill Livingstone, third edition

Suppe, F. (1977). The structure of scientific theories. Urbana: University of Illinois Press.

Taylor, C. (1989). Sources of the self: The making of the modern identity. Cambridge, MA: Harvard University Press.

Taylor, C. (1995). Philosophical arguments. Cambridge, MA: Harvard University Press.

Teasdale, J. D., Segal, Z. V., Williams, J. M. G., Ridgeway, V. A., Soulsby, J. M., \& Lau, M. A. (2000). "Prevention of relapse/recurrence in major depression by mindfulness-based cognitive therapy." Journal of Consulting and Clinical Psychology, 68, 615-623.

Teri, L., Gibbons, L. E., McCurry, S. M., Logsdon, R. G., Buchner, D. M., Barlow, W. E. et al. (2003). "Exercise plus behavioral management in patients with Alzheimer Disease: $A$ randomized controlled trial". Journal of the American Medical Association, 290, 2015-2022.

Warnke, G. (1987). Gadamer: Hermeneutics, tradition and reason. Stanford, CA: Stanford University Press.

Westen, D., \& Morrison, K. (2001). "A multidimensional metaanalysis of treatments for depression, panic, and generalized anxiety disorder: An empirical examination of the status of empirically supported therapies." Journal of Consulting and Clinical Psychology, 69, 875-899.

Westen, D., Novotny, C.M. \& Thompson-Brenner, H. (2004). "The Empirical Status of Empirically Supported Psychotherapies: Assumptions, Findings, and Reporting in Controlled Clinical Trials". Psychological Bulletin, 130, 631-663.

Wilson, G. T., \& Fairburn, C. G. (2002). "Treatments for eating disorders". In P. E. Nathan, P.E. and\& J. M. Gorman J.M. (Eds.), A guide to treatments that work ( $2^{\text {nd }}$ ed., pp. 559592). New York: Oxford University Press.

Woolfolk, R. L. (1998). The cure of souls: Science, values, and psychotherapy. San Francisco, CA, USA: Jossey-Bass Inc, Publishers.

Zoellner, L. A., Feeny, N. C., Cochran, B., \& Pruitt, L. (2003). "Treatment choice for PTSD" Behaviour Research and Therapy, 41, 879-886. 